\title{
Measuring Independent and Controlled Effects of Age at First Marriage and Age at First Birth on Completed Family Size among Women Aged 45-49 in Zambia
}

\author{
Nkuye Moyo ${ }^{1,2^{*}}$, Tina Nanyangwe-Moyo ${ }^{1}$, Xiaochun Qiao ${ }^{1}$, Jilei $\mathrm{Wu}^{1}$ and Xiaoying Zheng ${ }^{1}$ \\ ${ }^{1}$ Institute of Population Research, Peking University, Beijing, China \\ ${ }^{2}$ Department of Population Studies, Great East Road Campus, University of Zambia, Lusaka, Zambia
}

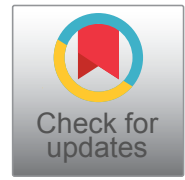

*Corresponding author: Nkuye Moyo, Institute of Population Research, Peking University, No. 5 Yiheyuan Road, Beijing, China, 100871; Department of Population Studies, University of Zambia, Great East Road Campus, Lusaka, Zambia 10101

\begin{abstract}
Background: The link between age at marriage and first birth in explaining completed family size is not always direct, due to heterogeneity in circumstances, that compel individual women to marry or initiate childbearing at a particular age. We analyzed data for 1020 women aged $45-$ 49 in 2014 of the 1965-1969 birth cohort from the 2013-14 Zambia Demographic and Health Survey (ZDHS).

Methods: We fitted a bivariate and multivariate multinomial logistic regression to establish the relationship between a mother's age at first marriage and at first birth on completed family size (CFS). Chi-square test of proportions measuring differences in proportions and relative risk ratios (RRR) with confidence intervals at $95 \%$ are reported.

Results: Our results show that the average CFS was 6.7 (95\% Cl: 6.5-6.9) among women completing their reproductive span in 2014 with mean age at first marriage and birth being 18.3 years (95\% Cl: 18.0-18.5) and 18.9 years (95\% Cl: $18.7-19.1)$ respectively. Women marrying at younger ages and having their first birth at younger ages were more likely (RRR: $1.187 ; 95 \% \mathrm{Cl}$ : 1.138-1.239 and RRR: $0.195 ; 95 \% \mathrm{Cl}: 0.074-0.511$ respectively) to have higher CFS than their compatriots that initiated both marriage and childbearing at or after age 22 controlling for covariates as presented in the controlled model. The independent effects model shows that the risk of having 1-3 children compared to 6 or more children was lower (RRR: 0.073; 95\% Cl: 0.009-0.611; RRR: 0.136 ; $95 \% \mathrm{Cl}: 0.046-$ 0.402 and RRR: $0.421 ; 95 \% \mathrm{Cl}: 0.135-1.312)$ for women whose ages at first marriage were $<15,15-18$ and 19-21 respectively relative to $22+$. Women with $1-3$ children were 2.5 times more likely to use contraception than women with 6 or more children.
\end{abstract}

Conclusion: Having no education, being a rural resident and having a medium household wealth all increase the risk of having higher CFS. Women that marry before age 19 have a higher likelihood of having 6 or more children by the end of their reproductive period. The study concludes that apart from a woman's age at first marriage and first birth, a complex network of factors interacts to determined CFS.

\section{Keywords}

Age at first marriage, Age at first birth, Completed family size, Fertility, Nulliparous

\section{Introduction}

Marriage assumes diverse denotations in different settings. Needless to say, every society has some form of a system which regulates the formation of a family and, one salient attribute of the act of family formation - called marriage [1], is that, it founds the basic unit of the social structure. Marriage is an institution where sexual intercourse is sanctioned and childbearing permitted \{Formatting Citation. Because of these two critical features, timing of entry into marriage, especially the age at which women first enter into a marital union becomes pivotal in measuring trends in fertility and patterns of completed family size (CFS) [1-4] and may hold greater sway in efforts to control fertility. Completed family size refers to the total number of children born to a woman during her child bearing age - generally considered to be $15-45$ years of age. Regardless of the average age at first sexual intercourse

Citation: Moyo N, Moyo TN, Qiao X, Wu J, Zheng X (2022) Measuring Independent and Controlled Effects of Age at First Marriage and Age at First Birth on Completed Family Size among Women Aged 45-49 in Zambia. Int J Womens Health Wellness 8:135. doi.org/10.23937/2474-1353/1510135 Accepted: February 07, 2022: Published: February 09, 2022

Copyright: (C) 2022 Moyo N, et al. This is an open-access article distributed under the terms of the Creative Commons Attribution License, which permits unrestricted use, distribution, and reproduction in any medium, provided the original author and source are credited. 
or magnitude of sexual activity in a society, unmarried women in any age group are unlikely to produce as many live births as married women in corresponding age groups because of social, cultural and economic penalties against out-of-wedlock childbearing [5-7] thus it is important to interrogate the extent to which timing of fertility events affect fertility itself.

In Zambia, marriage begins early $-46 \%$ of women age $20-49$ marry by age 18 , and 66 percent by age 20 and it is, by and large, universal as $78 \%$ women and 90\% men aged 35-39 are married [3,8]. As early as women enter into a marital union so does the onset of childbearing. The 2013-14 Zambia Demographic and Health Survey (ZDHS) report indicates that $31 \%$ of women in age cohort 20-24 in Zambia have had a first birth by exact age $18,50 \%$ by age 19 and, $61.3 \%$ by age 20 [8]. Tendencies where childbearing is concentrated at younger ages exert substantial influence on fertility levels because of early marriage rates. Studies suggest that women who marry young are predisposed to three core demographic aspects which influence high fertility and larger CFSs: High frequency of sexual intercourse throughout their most fecund years; the early onset of childbearing and an extended period of exposure to the risk of conception $[5,9,10]$. The confluence of these factors plunges a population where women marry young into a cycle of high fertility.

As is the case for Zambia, aggregate fertility levels remain one of the highest in sub-Saharan Africa and globally [8]. Although fertility rates continue to exhibit falling trends, the pace is not robust enough. The total fertility rate (TFR) progressively declined from 6.5 births per woman in 1992, 6.1 in 1996, 5.9 in 2010 and currently to 5.3 in 2014 [2,3,8,11,12]. In the short and medium term, fertility rates are expected to remain well above replacement as demonstrated by the number of children born to women nearing the end of their reproductive years (mean parity of 7 children) [8]. This study is well aware that the link between age at marriage and age first birth in explaining completed family size is not always direct due to heterogeneity in circumstances that compel individual women to marry or initiate childbearing at a particular age. Social, economic and cultural factors potentially influence the age at which women marry or have their first birth which are important correlates in explaining CFS. The study was motivated by the fact that a precise understanding of relationships in marriage trends and dynamics thereof are important in identifying causes confounded by intricate socioeconomic factors. Therefore, the aim of the study was to investigate the independent and controlled associations of age at first entry into marriage and age at first birth on CFS for women aged 45-49.

\section{Literature Review}

Scholarly investigations of the relationship between timing of marriage and that of first birth with completed family size are in abundance. Completed family size remains high in most African countries south of the Sahara due to a delayed onset of fertility transition $[13,14]$. World-wide comparison show that Africa is yet to undergo or has just begun the fertility transition and though a noticeable decline in fertility has been achieved, African fertility is still the highest when related other regional blocks [15].

The pathways that describe sexual debut and its effect on fertility is somewhat different for young men and women. Studies have shown that education plays a crucial role in adolescents' initiation to sexual activity. Most studies have shown that sexual activity, pregnancy and marriage are direct impediment to education attainment especially at secondary school level [16] and that dropping out of school is the main pathway to a myriad of reproductive events of sexual activity, pregnancy, or marriage $[17,18]$, that inevitably threatens completion of secondary school prospects. Research indicates that more girls than boys that are sexually active drop out of school [19], and that sexual activity is more detriment to girls' than boys' education [20]. This effect of early sexual activity and its eventual effect on school drop-out contributes to elevated premarital fertility among young people especially in countries that have improved ages at marriage. Another study found that girls that were already falling behind in studies at school had a higher probability of engaging in sexual activity than their counterparts who were doing well [21,22].

TFR in Zambia reduced from 6.1 in 1992, 5.9 in 2010, 5.3 in 2014 to 4.7 in 2018 [8,11,23,24]. This latest TFR is higher than the current average for most of the African region $[25,26]$. Though fertility has been declining in Africa, it remains high in comparison to other regions [26]. TFRs in the African region averaged 4.7 between 2010 and 2015 which is far above the global average of 2.5 though it is expected to drop by 2050, but will still be well above the rest of the world [27]. This high TFR fuels the next generation of mothers who will have fewer children than their preceding cohorts, but still more than the rest of the world. At this rate of fertility change, Africa will constitute $41 \%$ of the world's population and $40 \%$ of global under-five children by $2050[26,27]$. Desire for family size is also driven by many factors such as education and wealth. A study conducted on East African countries found enormous heterogeneity in CFS [28]. It concluded that "Wealthy and highly educated people have fertility desires close to replacement level, regardless of religion, while poor, uneducated people, particularly those of Muslim faith, have virtually uncontrolled fertility" [28]. This somewhat confirms the assertion that higher fertility which is linked with early childbearing leads to reduced investments in the education and health of each child [29], which contributes to the intergenerational flow of poverty [30]. 
The first time a woman enters marriage has huge implications on her health and that of her forthcoming offspring. Early systematic scholarly works by Lesthaeghe and colleagues [31,32] brought to light changes in age at marriage signifying an upward trend in most African countries. Many other scholars have undertaken extensive retrospective investigations that have added to the existing evidence of the increasing age at first marriage for African females [33-39]. More recent findings by Hertrich confirm substantial change in first marriage patterns across the continent [40]. Work by Hertrich confirms an inverse relationship between age at first marriage and fertility; the higher the age at marriage the lower the fertility and vice versa [40].

The time an individual starts parenthood is one of life's most challenging yet significant occurrences. A study based on DHS data of 43 countries found that the mean age at first birth was greater than the mean age at first marriage, which was also greater than the mean age at first sex for all regions [25]. Another study in Madagascar found that the effect of being married for 0-3 years was positive and statistically significant, and for being married 3-6 years negative and statistically significant in as far as having a first birth is concerned implying that the probability of having a first birth is higher during the first years of marriage, but diminishes after the third year [30]. Several studies in the region posit that the mean age at first birth in sub Saharan Africa is about 21 with most of West and Middle African countries having age at first birth at or below 18 years while East and Southern African countries above 22 years $[14,25,35]$. The increasingly rising age at first birth in most African countries could be as a result of improved education outcomes for women which would translate in better health and reduced risks of maternal related morbidity and mortality and manageable fertility. Generally, reproductive indicators for women (age at sexual debut, first marriage and first birth) play a crucial role in determining the fertility levels and trends for any country.

Our review of literature revealed that no known study during the time of this investigation has been conducted to examine the influence of age at first marriage and age at first on completed family size in Zambia. This study, therefore, provides groundbreaking evidence of the nature of relationship that exists between ages at marriage and first child birth on the one hand and CFS on the other. It spurs avenues to conduct research on other factors affecting CFS such as sociocultural constructs which influence choice of desired family size.

\section{Methods and Data}

This study utilized data from the 2013-14 Zambia Demographic and Health Survey (ZDHS). ZDHS is a population-based cross-sectional study dedicated to investigating health status of the Zambia people. A detailed discussion on the methodology of the ZDHS is available elsewhere [8]. The ZDHS protocol review ethical clearance was conducted by the following Institutional review boards (IRBs)/ethics committees: TDRC Ethical Review Committee, the Institutional Review Board of ICF International, and the CDC. Thus, this study needed no further ethical clearance as it used an individual de-identified data file with no possibility of identifying ZDHS study participants. Data for this study were procured from the DHS Program [41]. Our analysis concentrates on women belonging to the 1965-1969 birth cohort aged 45-49 during data collection for the 2013-14 ZDHS round.

Eligibility to the study was age-based thus neither marital status nor parity was a determinant for inclusion in the study. A total of 1020 women aged 45-49 in 2013 were enumerated. The ZDHS obtained information on lifetime fertility of women that had completed childbearing and further analyzed the average number of children born to women by the end of their reproductive cycle. This information was important in measuring and understanding CFS. We conducted a retrospective analysis of how age at first marriage and age at first birth affect the CFS of women during their childbearing period. We fitted a multinomial regression model that regressed age at first marriage and age at first birth on CFS and controlled for contraception use, education, place of residence and household wealth.

\section{Measures}

Outcome: The number of children born alive to each woman nearing the end of their reproductive period (CFS) was our outcome variable. Having established that CFS was non-linear with 15 categories, we recoded this variable to reduce the number of categories into low, medium and high parity. We ended up with four categories for CFS; 0, 1-3, 4-5 and 6+ relating to nulliparous, low, medium and high parity respectively. Categorizing parity into these groups is for analytical use only hence subjective.

Predictors: The study utilized two main predictors; 1) Age at first birth to investigate the extent to which age of the mother at birth of first child impacts on CFS and, 2) Age at first marriage, to assess the influence marriage exerts on completed fertility. Due to concerns of legal marriage age, we considered segmenting the age of mother at first marriage predictor variable in two parts, i.e. those marrying before 18 and those marrying after age 18. Two other categories were constructed for those who marry before and after age 18; ages $<15$ and 15-18 as well as ages 19-21 and 22 and above. Similarly, in terms of age at first birth, we considered those having their first child before 18 and those after 18 . This we, discerned, should provide us with some understanding of differences in completed family size for women marrying early (before age 18) and those marrying at and after the legal age. Zambia practices a dual legal system, comprising both customary and statutory 
laws. Marriages under customary law require that partners marrying have reached puberty; have parental consent to marry; have negotiated and paid bride price (lobola); and have performed a marriage ritual [42,43]. Conversely, under the statutory law, marriages are regulated under the Marriage Act [44]. All persons who marry must be at minimum 21 years of age and that in the event a person less than 21 years intends to marry, parental consent is required [44]. However, the law is silent on the minimum age that parents can consent to for marriage but does allow the high court judge to consent for a person below age 16 to marry $[42,43,45]$.

Covariates: Fertility among women varies greatly by socioeconomic characteristics. Traditionally, women with more education are more likely to have fewer children than those with no education. This observation holds true for household wealth holding other factors constant. We included a list of covariates to control for the influence of socioeconomic factor in measuring this relationship. The variables identified as having an association with CFS and thus used for modeling were contraception use, education, place of residence and household wealth.

Statistical analysis: During data exploration, we noticed that the relationship between our outcome variable (CFS) and our predictor variables (age at first marriage and age at first birth) was non-linear. Because of the non-linearity of CFS and the polytomous nature of its categories, we fitted a multinomial logistic regression (MLR) to measure the level and amount of association between our outcome and predictor variables. The MLR is similar to the binary logistic regression except that it is more versatile as it can handle an outcome variable with more than two categories. To determine associations of the outcome variable with the predictor variables, descriptive analyses were performed mainly as proportions utilizing chi-square tests of proportions and results presented in terms of percentages with confidence intervals. We calculated the mean CFS for women in this study, their mean ages at birth and marriage as well as their confidence intervals. We also graphed our data using a fractional polynomial to illustrated predictor-outcome relationship.

In building our MLR model, we first examined the relationship between each predictor variable (one at a time) and CFS through bivariate analysis (model 1 ). In model 2, we fitted a multivariate MLR model that included all predictor variables in model 1 i.e. mother's age at first marriage and mother's age at first birth and additionally controlled for potential confounders: education, place of residence, household wealth and contraceptive use. In model 3, we included all the variables that showed the strongest associations with the outcome but deliberately dropped mother's age at first birth to check for the effect of correlation between the two predictor variables. In model 4 , we brought back mother's age at first birth and this time removed mother's age at first marriage from analysis for the same reason as in model 3.

Understanding the risk of multicollinearity, standard errors for all variables were interrogated with the addition of each variable to the model for indications of instability. Missing data were interrogated to determine the best way to handle them. We found that missing data comprised two groups. The first related to age at first birth. Upon performing crosstabulations of CFS and age at first birth, we found that all the missing data on age at first birth were due to 25 nulliparous women $(2.45 \%)$. Second, we found that 8 women $(0.78 \%)$ in our sample had missing age at first marriage. We performed a multivariate normal (MVN) distribution procedure to implement a Multiple Imputation (MI) technique that utilizes the Markov Chain Monte Carlo (MCMC) argumentation to impute the 8 women missing age at first marriage. Regarding the 25 women missing "Age at 1st birth" data, we have decided not to impute this data as doing so will smoothen genuine irregularities since the missing data in this case is because the 25 women in question had never had a birth hence nulliparous. We reported relative risk ratios (RRR) for all our models with their corresponding confidence intervals at $95 \%$. Data weighting was conducted in Stata prior to performing any analyses and the generated results are representative of the study population. All analyses were performed in Stata 14 [46].

\section{Results}

\section{Descriptive findings}

The 2014 ZDHS identified 1,020 women belonging to the 1965-1969 cohort aged between 45-49 during the survey. Our findings indicate that the average CFS was 6.7 (95\% Cl: 6.5-6.9) and the average age at first marriage for this cohort of women was 18.3 years $(\mathrm{Cl}$ : 18.0-18.5) while the mean age at first birth was 18.9. Table 1, presents descriptive findings based of the characteristics of the respondents.

In terms of contraceptive use, over half (53.2\%; $\mathrm{Cl}$ : 50.5-56.8) reported ever using a method of contraception to prevent pregnancy. Fifty-nine percent ( $\mathrm{Cl}$ : 55.6-61.8) of respondents were rural dwellers. Fifty-three percent ( $\mathrm{Cl}$ : 49.5-55.7) had no education followed by $39.7 \%$ (Cl: 36.7-42.8) with primary education. The remaining 3.0\% ( $\mathrm{Cl}: 2.0-4.2)$ and $4.7 \%(\mathrm{Cl}: 3.5-6.2)$ had secondary and tertiary education respectively as presented in Table 2.

A chi-square test of differences in proportions in Table 2 shows association of mother's characteristics and CFS. All the Pearson's chi-square tests show statistically significant associations between each characteristic of the mother and CFS.

A comparison of CFS by age at first marriage and place of residence revealed that regardless of dwelling 
Table 1: Background characteristics of respondents.

\begin{tabular}{|l|l|l|l|l|}
\hline Variable & $\mathbf{n}$ & Mean & Standard Error & 95\% Confidence Intervals \\
\hline Completed Family Size (CFS) & 1,020 & 6.7 & 0.093 & $6.5,6.9$ \\
\hline Age of respondent at first birth & 995 & 18.9 & 0.120 & $18.7,19.1$ \\
\hline Age at first Marriage & 1012 & 18.3 & 0.142 & $18.0,18.5$ \\
\hline Age of women aged 45-49 in single years & 1,020 & 47.0 & 0.047 & $46.9,47.1$ \\
\hline
\end{tabular}

Table 2: Chi-square test of difference in proportions of completed family size.

\begin{tabular}{|c|c|c|c|c|c|c|c|}
\hline & \multicolumn{5}{|c|}{ Completed Family Size } & \multirow[b]{2}{*}{$95 \% \mathrm{Cls}$} & \multirow[b]{2}{*}{ P-Value } \\
\hline & 0 & $1-3$ & $4-5$ & $6+$ & Total & & \\
\hline \multicolumn{2}{|c|}{$\begin{array}{l}\text { Mother's age at first } \\
\text { marriage }\end{array}$} & & & & & & 0.000 \\
\hline$<15$ & $1(0.1)$ & $13(1.28)$ & $14(1.38)$ & $109(10.77)$ & $137(13.54)$ & $11.5,15.8$ & \\
\hline $15-18$ & $7(0.69)$ & $31(3.06)$ & $68(6.72)$ & $412(40.71)$ & $518(51.2)$ & $48.1,54.3$ & \\
\hline $19-21$ & $6(0.6)$ & $30(3.0)$ & $44(4.4)$ & $114(11.3)$ & $194(19.2)$ & $16.8,21.7$ & \\
\hline $22+$ & $7(0.7)$ & $63(6.2)$ & $37(3.7)$ & $56(5.5)$ & $163(16.1)$ & $13.9,18.5$ & \\
\hline Total & $21(2.1)$ & $137(13.5)$ & $163(16.1)$ & $691(68.3)$ & $1012(100)$ & & \\
\hline \multicolumn{2}{|c|}{ Mother's age at first birth } & & & & & & 0.000 \\
\hline$<15$ & & $7(0.7)$ & $5(0.5)$ & $47(4.7)$ & $59(5.9)$ & $4.5,7.6$ & \\
\hline $15-18$ & & $34(3.4)$ & $51(5.1)$ & $396(39.8)$ & $481(48.3)$ & $45.2,51.5$ & \\
\hline $19-21$ & & $42(4.2)$ & $63(6.3)$ & $181(18.2)$ & $286(28.7)$ & $25.9,31.6$ & \\
\hline $22+$ & & $57(5.7)$ & $45(4.5)$ & $67(6.7)$ & $169(17.0)$ & $14.7,19.5$ & \\
\hline Total & & $140(14.1)$ & $164(16.5)$ & $691(69.5)$ & $995(100)$ & & \\
\hline \multicolumn{2}{|c|}{ Place of residence } & & & & & & 0.000 \\
\hline Urban & $12(1.2)$ & $85(8.3)$ & $76(7.5)$ & $248(24.3)$ & $421(41.3)$ & $38.2,44.4$ & \\
\hline Rural & $13(1.3)$ & $55(5.4)$ & $88(8.6)$ & $443(43.4)$ & $599(58.7)$ & $55.6,61.8$ & \\
\hline Total & $25(2.5)$ & $140(13.7)$ & $164(16.1)$ & $691(67.8)$ & $1020(100)$ & & \\
\hline \multicolumn{2}{|c|}{ Ever used contraception } & & & & & & 0.000 \\
\hline Yes & $2(0.2)$ & $53(5.2)$ & $70(6.9)$ & $418(41.0)$ & $543(53.2)$ & $50.5,56.8$ & \\
\hline No & $23(2.3)$ & $87(8.5)$ & $94(9.2)$ & $273(26.8)$ & $477(46.8)$ & $44.0,50.3$ & \\
\hline Total & $25(2.5)$ & $140(13.7)$ & $164(16.1)$ & $691(67.8)$ & $1020(100)$ & & \\
\hline \multicolumn{2}{|c|}{ Education } & & & & & & 0.000 \\
\hline No education & $12(1.2)$ & $48(4.7)$ & $63(6.2)$ & $414(40.6)$ & $537(52.6)$ & $49.5,55.7$ & \\
\hline Primary & $9(0.9)$ & $55(5.4)$ & $75(7.4)$ & $266(26.1)$ & $405(39.7)$ & $36.7,42.8$ & \\
\hline Secondary & $1(0.1)$ & $13(1.3)$ & $11(1.1)$ & $5(0.5)$ & $30(3.0)$ & $2.0,4.2$ & \\
\hline Tertiary & $3(0.3)$ & $24(2.4)$ & $15(1.5)$ & $6(0.6)$ & $48(4.7)$ & $3.5,6.2$ & \\
\hline Total & $25(2.5)$ & $140(13.7)$ & $164(16.1)$ & $691(67.8)$ & $1020(100)$ & & \\
\hline \multicolumn{2}{|c|}{ Household wealth } & & & & & & 0.000 \\
\hline Lowest & $4(0.39)$ & $16(1.57)$ & $31(3.04)$ & $135(13.24)$ & $186(18.24)$ & $15.9,20.7$ & \\
\hline Second & $1(0.1)$ & $19(1.86)$ & $28(2.75)$ & $158(15.49)$ & $206(20.2)$ & $17.8,22.8$ & \\
\hline Middle & $6(0.59)$ & $19(1.86)$ & $31(3.04)$ & $173(16.96)$ & $229(22.45)$ & $19.9,25.1$ & \\
\hline Fourth & $5(0.49)$ & $25(2.45)$ & $34(3.33)$ & $138(13.53)$ & $202(19.8)$ & $17.4,22.4$ & \\
\hline Highest & $9(0.88)$ & $61(5.98)$ & $40(3.92)$ & $87(8.53)$ & 197 (19.31) & $16.9,21.9$ & \\
\hline Total & $25(2.45)$ & $140(13.73)$ & $164(16.08)$ & $691(67.75)$ & $1020(100)$ & & \\
\hline
\end{tabular}

place, more women that got married before age 15 and those that married between ages 15 and 18 had 6 or more children than those marrying after age 18 . A small proportion (25.9\%) of women who bore 6 or more children were those from urban areas that got married after age 21. Figure 1 further demonstrates that more than half $(51.8 \%)$ of urban women marrying at ages above 21 had 1-3 children compared to their rural compatriots at only $24.4 \%$. For all ages at marriage except before age 15, the proportion of women who 


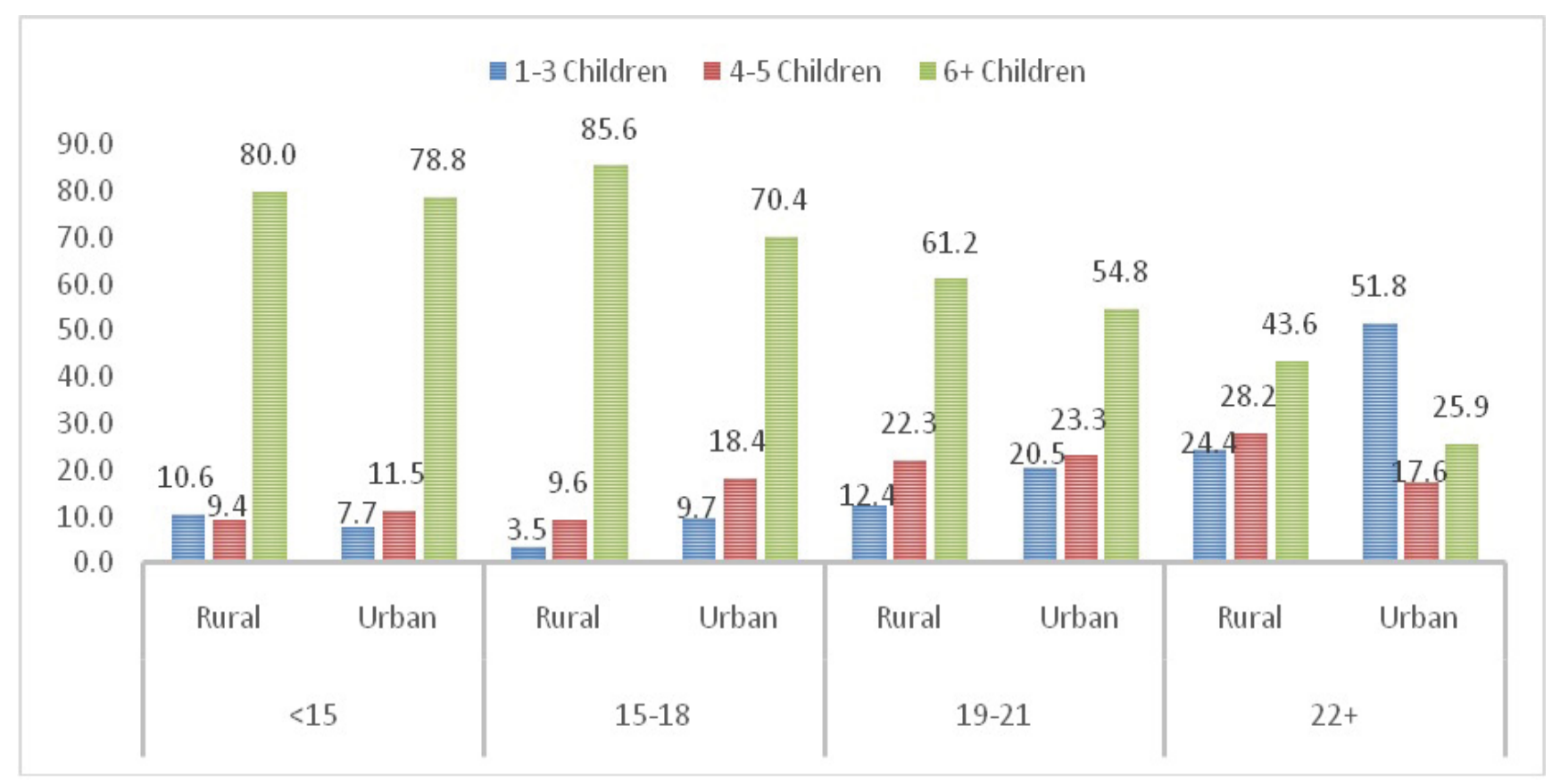

Figure 1: Completed family size by age at first marriage and residence.

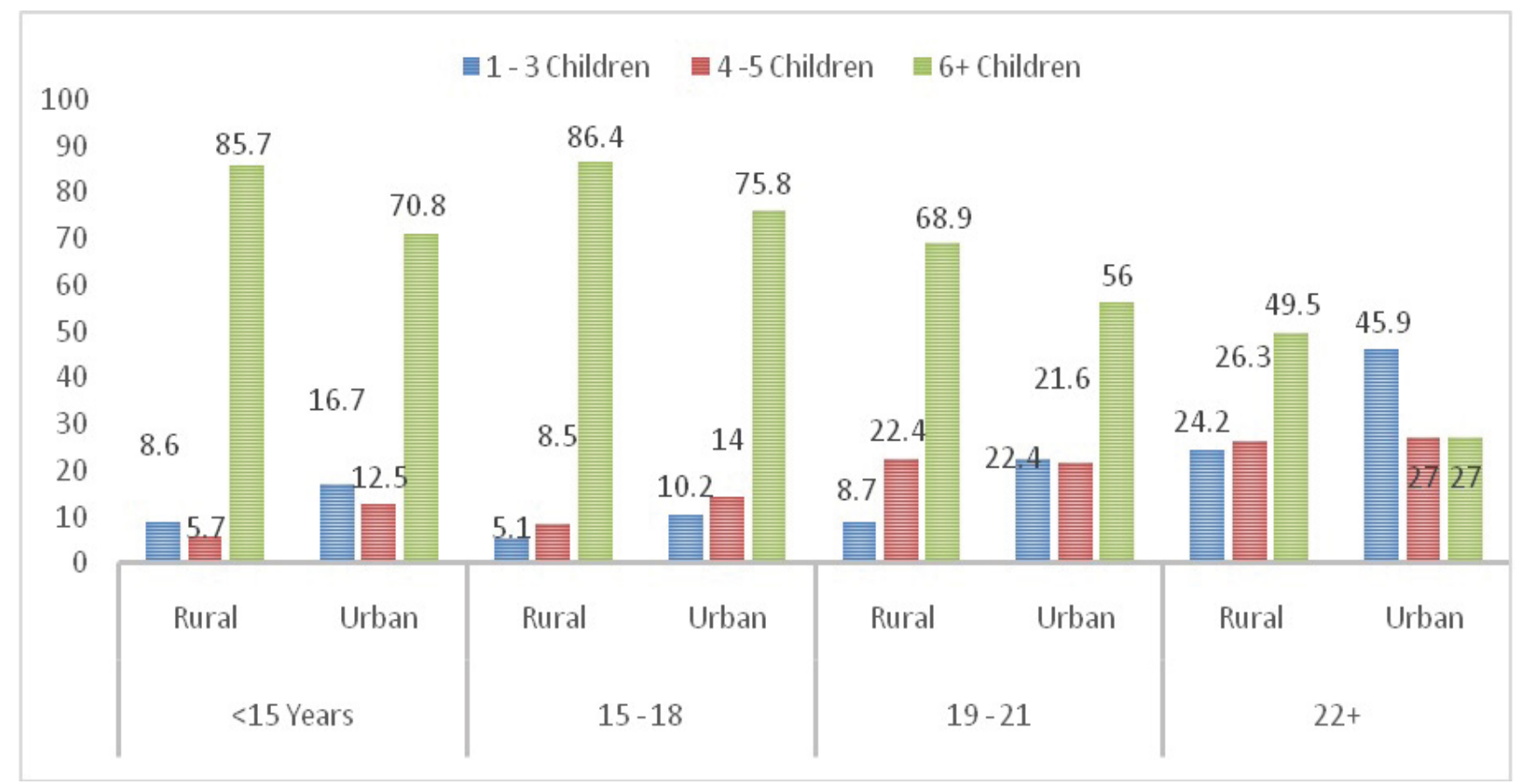

Figure 2: Completed family size by mother's age at first birth and residence.

had 1-3 children is lower for rural compared to urban areas. Figure 1 describes differences in CFS by age at first marriage for urban and rural women aged 45-49.

Analysis by place of residence illustrates that, both urban and rural women exhibit a distinct pattern of CFS. The proportions of rural women with 6 or more children were relatively higher for all ages at first birth when compared with their urban counterparts. For instance, the proportions of women having 6 or more children increased with age at first birth from $85.7 \%$ for those who had their first birth before age 15 to $86.4 \%$ for those who had their first birth at ages between 15 and
18 inclusive. As age at first birth increases, higher parity gradually diminish while proportions rise for lower parity. Figure 2, depicts this scenario.

\section{Bivariate analysis}

The risk of having 1-3 children compared to 6 or more children was $89.4 \%, 93.3 \%$ and $76.6 \%$ lower for women whose ages at first marriage were $<15,15-18$ and 19-21 respectively relative to $22+$. Women with $1-3$ children were 2.5 times more likely to use contraception than women with 6 or more children. Other characteristics that had statistically significant associations were 
Table 3: Model 1: Bivariate multinomial regression of children ever born by characteristics of mother.

\begin{tabular}{|c|c|c|c|}
\hline \multirow{2}{*}{\begin{tabular}{|l} 
Children ever born \\
0 Children
\end{tabular}} & \multirow[t]{2}{*}{ RRR } & \multicolumn{2}{|c|}{$\begin{array}{l}\text { 95\% Confidence } \\
\text { Intervals }\end{array}$} \\
\hline & & & \\
\hline \multicolumn{4}{|l|}{ Age at first marriage } \\
\hline$<15$ & $0.073^{*}$ & 0.009 & 0.611 \\
\hline $15-18$ & $0.136^{* * *}$ & 0.046 & 0.402 \\
\hline $19-21$ & 0.421 & 0.135 & 1.312 \\
\hline \multicolumn{4}{|l|}{ 22+ (Reference) } \\
\hline \multicolumn{4}{|c|}{ Ever used Contraception } \\
\hline No & $17.608^{* * *}$ & 4.118 & 75.286 \\
\hline \multicolumn{4}{|l|}{ Yes (Reference) } \\
\hline \multicolumn{4}{|l|}{ Education attainment } \\
\hline No education & $0.058^{* * *}$ & 0.013 & 0.260 \\
\hline Primary & $0.068^{\star *}$ & 0.015 & 0.315 \\
\hline Secondary & 0.400 & 0.031 & 5.151 \\
\hline \multicolumn{4}{|l|}{ Tertiary (Reference) } \\
\hline \multicolumn{4}{|l|}{ Place of residence } \\
\hline Rural & 0.606 & 0.273 & 1.350 \\
\hline \multicolumn{4}{|l|}{ Urban (Reference) } \\
\hline \multicolumn{4}{|l|}{ Household Wealth } \\
\hline Lowest & $0.286^{*}$ & 0.086 & 0.959 \\
\hline Second & $0.061^{\star *}$ & 0.008 & 0.491 \\
\hline Middle & $0.335^{*}$ & 0.116 & 0.972 \\
\hline Fourth & 0.350 & 0.114 & 1.080 \\
\hline \multicolumn{4}{|l|}{ Highest (Reference) } \\
\hline \multicolumn{4}{|l|}{ 1-3 Children } \\
\hline \multicolumn{4}{|l|}{ Age at first birth } \\
\hline$<15$ & $0.175^{* * *}$ & 0.073 & 0.417 \\
\hline $15-18$ & $0.101^{\star \star *}$ & 0.061 & 0.166 \\
\hline $19-21$ & $0.273^{* * *}$ & 0.168 & 0.444 \\
\hline \multicolumn{4}{|l|}{ 22+ (Reference) } \\
\hline \multicolumn{4}{|l|}{ Age at first marriage } \\
\hline$<15$ & $0.106^{* * *}$ & 0.054 & 0.209 \\
\hline $15-18$ & $0.067^{* * *}$ & 0.040 & 0.112 \\
\hline $19-21$ & $0.234^{* * *}$ & 0.136 & 0.401 \\
\hline \multicolumn{4}{|l|}{$22+$ (Reference) } \\
\hline \multicolumn{4}{|c|}{ Ever used Contraception } \\
\hline No & $2.513^{*+*}$ & 1.729 & 3.653 \\
\hline \multicolumn{4}{|l|}{ Yes (Reference) } \\
\hline \multicolumn{4}{|l|}{ Education attainment } \\
\hline No education & $0.029^{* * *}$ & 0.011 & 0.074 \\
\hline Primary & $0.052^{* * *}$ & 0.020 & 0.132 \\
\hline Secondary & 0.650 & 0.166 & 2.546 \\
\hline \multicolumn{4}{|l|}{ Tertiary (Reference) } \\
\hline \multicolumn{4}{|l|}{ Place of residence } \\
\hline Rural & $0.362^{* * *}$ & 0.249 & 0.526 \\
\hline \multicolumn{4}{|l|}{ Urban (Reference) } \\
\hline Household Wealth & & & \\
\hline
\end{tabular}

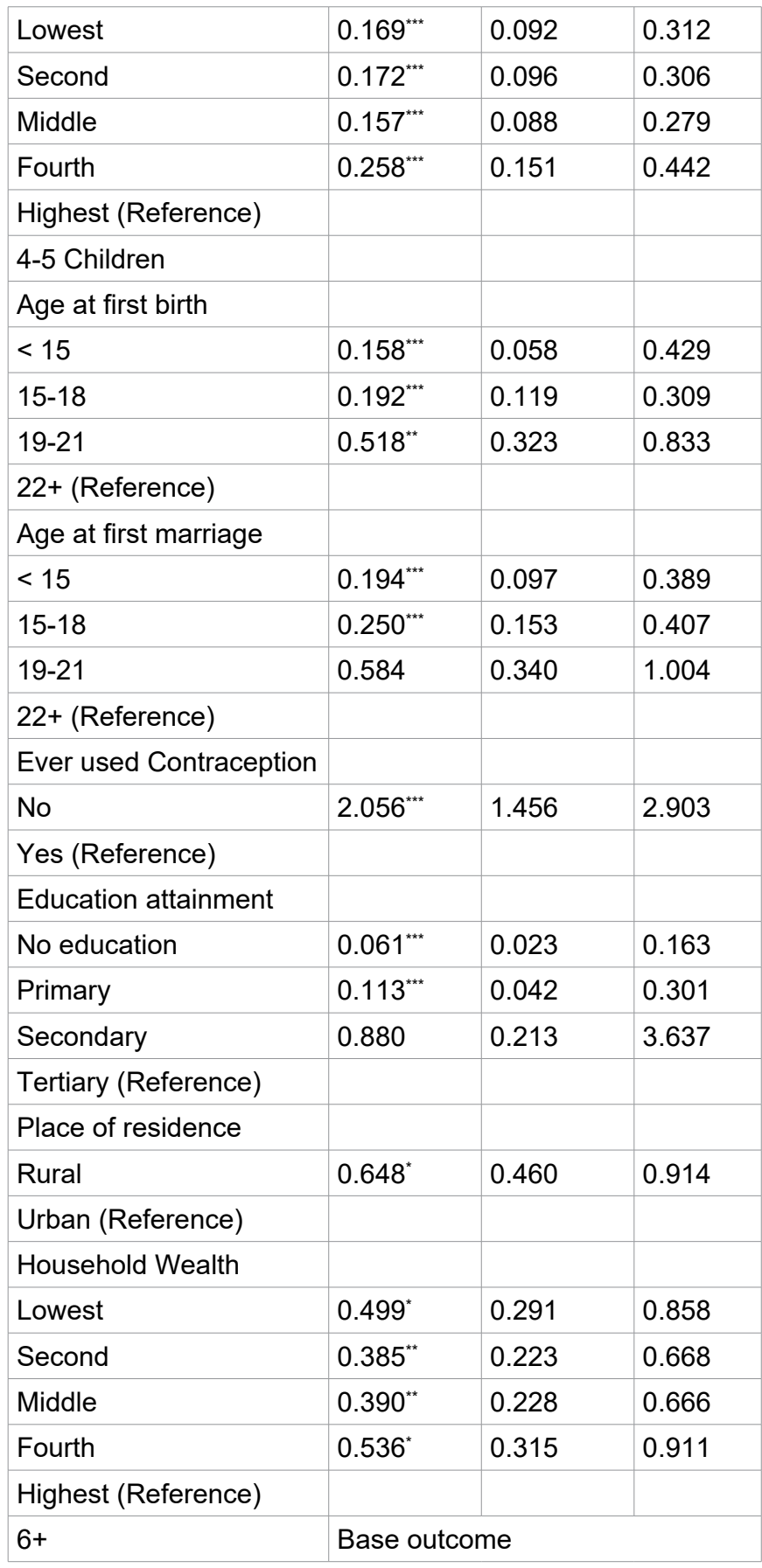

${ }^{* * *} \mathrm{P}<0.001 ;{ }^{* *} \mathrm{P}$ is $<0.01$ and $\geq 0.001 ;{ }^{*} \mathrm{P} \leq 0.05$ and $\geq 0.01$.

education (no education and primary), place of residence and household wealth. Similar results were observed for women with 4-5 children when compared to those with 6 or more children. See Table 3 for details.

\section{Multivariate analysis}

Table 4 presents multivariate MLR determining the relationship between CFS and the characteristics of the mother. When both the mother's age at first marriage and at first birth were simultaneously included in the regression model (model 2), the model did not run results for 0 births because age at first birth for women who are nulliparous is not applicable. While model 3 omitted mother's age at first birth and model 4 omitted mother's age at first marriage hence the missing coefficients, model 2 included all the predictor variables 
Table 4: Multivariate multinomial regression of children ever born by characteristics of the mother.

\begin{tabular}{|c|c|c|c|c|c|c|c|c|c|}
\hline \multirow[b]{2}{*}{ CFS } & \multicolumn{3}{|c|}{ Model 2} & \multicolumn{3}{|c|}{ Model 3} & \multicolumn{3}{|c|}{ Model 4} \\
\hline & RRR & \multicolumn{2}{|c|}{$95 \% \mathrm{Cl}$} & $\exp (b)$ & \multicolumn{2}{|c|}{$95 \% \mathrm{Cl}$} & RRR & \multicolumn{2}{|c|}{$95 \% \mathrm{Cl}$} \\
\hline \multicolumn{10}{|l|}{0} \\
\hline Age at $1^{\text {st }}$ Marriage & & & & $1.181^{* * *+}$ & 1.096 & 1.273 & & & \\
\hline \multicolumn{10}{|c|}{ Ever use contraceptive } \\
\hline \multicolumn{10}{|l|}{ No } \\
\hline \multicolumn{10}{|l|}{ Yes (Reference) } \\
\hline \multicolumn{10}{|l|}{ Education } \\
\hline No education & & & & 0.346 & 0.057 & 2.105 & & & \\
\hline Primary & & & & 0.210 & 0.041 & 1.080 & & & \\
\hline Secondary & & & & 0.531 & 0.040 & 7.020 & & & \\
\hline \multicolumn{10}{|l|}{ Tertiary (Reference) } \\
\hline \multicolumn{10}{|l|}{ Household Wealth } \\
\hline Lowest & & & & 0.303 & 0.069 & 1.337 & & & \\
\hline Second & & & & $0.067^{*}$ & 0.007 & 0.623 & & & \\
\hline Middle & & & & 0.413 & 0.117 & 1.464 & & & \\
\hline Fourth & & & & 0.440 & 0.125 & 1.552 & & & \\
\hline \multicolumn{10}{|l|}{ Highest (Reference) } \\
\hline \multicolumn{10}{|l|}{ Residence } \\
\hline \multicolumn{10}{|l|}{ Rural } \\
\hline \multicolumn{10}{|l|}{ Urban (Reference) } \\
\hline $1-3$ & & & & & & & & & \\
\hline Age at $1^{\text {st }}$ Marriage & $1.146^{\star \star \star}$ & 1.092 & 1.203 & $1.187^{*+*}$ & 1.138 & 1.239 & & & \\
\hline Age at $1^{\text {st }}$ Birth & & & & & & & & & \\
\hline$<15$ & 0.564 & 0.199 & 1.598 & & & & $0.195^{\star *}$ & 0.074 & 0.511 \\
\hline $15-18$ & $0.300^{* * *}$ & 0.161 & 0.560 & & & & $0.148^{* * *}$ & 0.085 & 0.261 \\
\hline $19-21$ & $0.505^{*}$ & 0.281 & 0.910 & & & & $0.344^{* * *}$ & 0.197 & 0.601 \\
\hline $22+$ (Reference) & & & & & & & & & \\
\hline Ever use contracept & & & & & & & & & \\
\hline No & $6.877^{\star \star \star}$ & 4.121 & 11.474 & & & & $6.592^{* * *}$ & 4.006 & 10.848 \\
\hline Yes (Reference) & & & & & & & & & \\
\hline Education & & & & & & & & & \\
\hline No education & $0.101^{* * *}$ & 0.032 & 0.319 & $0.144^{* * *}$ & 0.049 & 0.425 & $0.076^{* * *}$ & 0.025 & 0.238 \\
\hline Primary & $0.144^{* * *}$ & 0.050 & 0.416 & $0.155^{* * *}$ & 0.057 & 0.423 & $0.128^{* * *}$ & 0.045 & 0.364 \\
\hline Secondary & 0.935 & 0.214 & 4.080 & 0.847 & 0.207 & 3.463 & 1.095 & 0.256 & 4.694 \\
\hline Tertiary (Reference) & & & & & & & & & \\
\hline Household Wealth & & & & & & & & & \\
\hline Lowest & $0.240^{* *}$ & 0.086 & 0.668 & $0.340^{* *}$ & 0.158 & 0.730 & $0.188^{* * *}$ & 0.083 & 0.424 \\
\hline Second & $0.268^{* *}$ & 0.106 & 0.680 & $0.331^{* *}$ & 0.162 & 0.676 & $0.220^{* * *}$ & 0.103 & 0.469 \\
\hline Middle & $0.279^{* *}$ & 0.121 & 0.640 & $0.311^{* *}$ & 0.157 & 0.613 & $0.240^{* * * *}$ & 0.117 & 0.491 \\
\hline Fourth & $0.361^{* *}$ & 0.179 & 0.728 & $0.461^{* *}$ & 0.246 & 0.863 & $0.364^{* *}$ & 0.188 & 0.707 \\
\hline Highest (Reference) & & & & & & & & & \\
\hline residence & & & & & & & & & \\
\hline Rural & 0.701 & 0.376 & 1.307 & & & & & & \\
\hline Urban (Reference) & & & & & & & & & \\
\hline $4-5$ & & & & & & & & & \\
\hline Age at $1^{\text {st }}$ Marriage & $1.057^{*}$ & 1.006 & 1.110 & $1.106^{\star * *}$ & 1.060 & 1.154 & & & \\
\hline
\end{tabular}




\begin{tabular}{|c|c|c|c|c|c|c|c|c|c|}
\hline \multicolumn{10}{|l|}{ Age at $1^{\text {st }}$ Birth } \\
\hline$<15$ & $0.272^{*}$ & 0.091 & 0.812 & & & & $0.179^{* *}$ & 0.063 & 0.506 \\
\hline $15-18$ & $0.333^{* * *}$ & 0.188 & 0.590 & & & & $0.253^{* * *}$ & 0.151 & 0.424 \\
\hline $19-21$ & 0.735 & 0.431 & 1.255 & & & & 0.630 & 0.377 & 1.055 \\
\hline \multicolumn{10}{|c|}{ 22+ (Reference) } \\
\hline \multicolumn{10}{|c|}{ Ever use contraceptive } \\
\hline No & $3.358^{* * *}$ & 2.240 & 5.036 & & & & $3.338^{\star \star \star}$ & 2.230 & 4.997 \\
\hline \multicolumn{10}{|c|}{ Yes (Reference) } \\
\hline \multicolumn{10}{|l|}{ Education } \\
\hline No education & $0.082^{* * *}$ & 0.026 & 0.255 & $0.090^{* * *}$ & 0.030 & 0.273 & $0.071^{* * *}$ & 0.023 & 0.219 \\
\hline Primary & $0.175^{\star *}$ & 0.060 & 0.509 & $0.163^{* *}$ & 0.057 & 0.464 & $0.161^{* *}$ & 0.056 & 0.469 \\
\hline Secondary & 1.164 & 0.267 & 5.069 & 0.963 & 0.229 & 4.045 & 1.206 & 0.277 & 5.250 \\
\hline \multicolumn{10}{|c|}{ Tertiary (Reference) } \\
\hline \multicolumn{10}{|c|}{ Household Wealth } \\
\hline Lowest & 1.076 & 0.452 & 2.559 & 1.324 & 0.676 & 2.594 & 0.894 & 0.440 & 1.817 \\
\hline Second & 0.856 & 0.380 & 1.931 & 0.940 & 0.487 & 1.813 & 0.724 & 0.365 & 1.436 \\
\hline Middle & 0.821 & 0.396 & 1.705 & 0.863 & 0.464 & 1.608 & 0.718 & 0.376 & 1.372 \\
\hline Fourth & 0.931 & 0.491 & 1.766 & 1.032 & 0.566 & 1.880 & 0.894 & 0.480 & 1.666 \\
\hline \multicolumn{10}{|c|}{ Highest (Reference) } \\
\hline \multicolumn{10}{|l|}{ residence } \\
\hline Rural & 0.794 & 0.471 & 1.338 & & & & & & \\
\hline \multicolumn{10}{|c|}{ Urban (Reference) } \\
\hline $6+$ & \multicolumn{9}{|c|}{ Base outcome } \\
\hline
\end{tabular}

${ }^{* * *} \mathrm{P}<0.001 ;{ }^{* *} \mathrm{P}$ is $<0.01$ and $\geq 0.001 ;{ }^{*} \mathrm{P} \leq 0.05$ and $\geq 0.01$.

and covariates. Statistical significance was established for mother's age at first birth (15-18 and 19-21), mother's age at first marriage, ever used contraception, education (no education and primary), and household wealth when CFS was 1-3 children relative to 6 or more children (see model 2). For mother's age at first birth, the risk of 1-3 children was statistically significant for women aged 15-18 and 19-21 (RRR: 0.3; 95\% Cl: 0.1610.560 and RRR: $0.505 ; 95 \% \mathrm{Cl}$ : 0.281-0.910). For 4-5 children, mother's age at marriage, mother's age at birth $(<15$ and 15-18), education and contraceptive use were statistically significant. Model 3 omitted mother's age at first birth, contraceptive use and residence from the model which strengthened the model as all coefficients were statistically significant for almost all categories. Contraceptive use was eliminated from model 2 due to an abnormally high standard error (above 2.5) and residence because it could not predict CFS well enough based on its non-statistically significant coefficients. Model 4 included the mother's age at first birth and omitted residence due to the same reasons as in model 3. The estimates were all statistically significant except for education and household wealth when CFS is 0 and household wealth when CFS is $4-5$. Table 4 details the results of the models.

Of particular interest in Model 3 was that women's age at first marriage was strongly related to both 1-3 children and 4-5 children parities. Except for women who had 4-5 children, household wealth had a statistically significant relationship with CFS in both model 3 and 4 . Women with primary and without education were more likely to have 6 or more children than 1-3 children relative to those with tertiary education. RRRs for model 2 and 3 for the respective variables were similar. Comparing the full model (model 2) with selectpredictor-omitted models (models 3 and 4), we found that women whose age at first birth was 15-18 and 1921 years were $70 \%$ and $49.5 \%$ respectively less likely to have a CFS of 1-3 children. While in model 4 , these groups of women were $85.2 \%$ and $65.6 \%$ less likely to have a smaller family compared to those whose age at first birth was 22 years or more. Relatedly, women who married before age 22 were less likely to have a small CFS than women that married at age 22 years or above (see model 2 and 3 ).

\section{Discussion}

This study analyzed fertility behavior data of 1,020 women born during the 1965-1969 cohort based on cross sectional-retrospective data in Zambia. Our results show that the average CFS was 6.7 (95\% Cl: 6.56.9) and that mean age at first marriage and first birth were 18.3 (95\% Cl: 18.0-18.5) and 18.9 (95\% Cl: 18.719.1) respectively. About $11 \%$ of women with CFS above 6 children married before age 15 and $5 \%$ had their first birth within the same age range. Higher CFS of 6 or more 
children were concentrated among women whose age at first marriage and birth was between 15 and 18 years old (40.7 and $39.8 \%$ respectively). Women marrying at younger ages and having their first birth at younger ages were more likely to have higher CFS than compatriots that initiated both marriage and childbearing at or after age 22 .

The main strength of this study is it followed a cohort of women who had or were about to complete their reproductive cycle and collected fertility information about this group in a manner that provided grounds for exploring determinant. The study also controlled for socioeconomic factors to effectively discern associations. Furthermore, the use of probability sampling in the collection of this data gives this study sufficient leverage to generalize findings to the entire 1965-1969 cohort in Zambia. However, our study also presents some limitations. As are all surveys that depend on retrospective responses, self-reported data may introduce biases such as social desirability bias, nonresponse bias, recall bias, interviewer bias etc., even in the presence of exceptionally trained enumerators and rigorous probing to encourage accuracy of reporting [47-49]. Women, especially in rural areas, might report children they have adopted (could be for a sister who died, husband children from an earlier marriage, etc.,) as their own due social desirability. People in traditional settings have a tendency not to count children that die shortly after birth as live birth. The primary limitation of the cross-sectional study design is that because the exposure and outcome are simultaneously assessed, there is generally no evidence of a temporal relationship between exposure and outcome $[49,50]$. However, since there exist a considerable amount of time lag between getting married and having children, a temporal relationship between age at first marriage, age at first birth and CFS can be established.

Understanding changes in CFS is an important indicator of the anticipated future in lifetime fertility behavior of women. Factors that influence these changes become cornerstones for predicting fertility behavior and determining population growth. This study found a CFS of 6.7 children for the 1965-1969 birth cohort based on retrospective data analysis. This finding is consistent with results from the 2013-14 ZDHS that also found the average number of children ever born was 6.7 for women nearing the end of their childbearing cycle and 7.3 for those currently married, alluding the difference in the two measures to lower fertility among the young unmarried women [8] in the former index. This CFS is higher than the current TFR for most African countries including Zambia itself $[25,26]$. TFR in Zambia reduced from 6.1 in 1992, 5.9 in 2010, 5.3 in 2014 to 4.7 in 2018 [8,11,23,24]. The CFS is the major determinant of the average household size that remains high in most African countries [51]. The household size in Zambia is high at 5.1 persons (urban 4.8 and rural 5.4) [8] relative to the TFR of 4.7 children.

Our study further found that women from the 19651969 cohort married early (mean $=18.3 ; \mathrm{Cl}$ : 18.0-18.5) and that by the end of their reproductive life, $68.3 \%$ of them had birthed 6 children or more. With changes in reproductive behaviors overtime, this rate is expected to be lower for future cohorts. In fact, a study conducted in Malawi found that older cohorts have higher fertility than younger ones [52]. As expected, marriage plays a crucial role in shaping the course of fertility, especially in the developing world [25]. The timing of marriage predominantly regulates how many children will be born since marriage is the only institution that sanctions reproduction. Over half $(51.2 \% ; \mathrm{Cl}$ : $48.1-54.3)$ of the women from our study married between age 15 and 18 and a substantial number $(13.5 \% \mathrm{Cl}: 11.5-15.8)$ married at ages below 15 years. Our analyses reveal that almost two-thirds (64.7\%) of women from this cohort were married off when they were still underage exposing them to a long period of the risk of childbearing. Fiftyone percent of women with 6 or more children got married by age 18 . Studies have shown that women that marry early, start childbearing early, remain at risk of childbearing for longer periods of times and have poor health outcomes than their counterparts who marry later $[53,54]$. The timing of marriage in Zambia is affected by a myriad of socioeconomic factors, including education, wealth, social status and cultural responsibility that influence CFS. This study found that the cohort under investigation generally had more children, but the probability of having fewer children was higher for urban women than rural women. To put this into perspective, one study investigated how household economic hard times affect the time of marrying off their children especially in Africa where payment for marriage, whether in cash or kind, is widespread. They found that parents tactfully selected the time for their children's marriage depending on household economic instability thus affecting age at marriage as the payments for marriage constitute a vital source for "consumption smoothing" for the bride's family [55].

A woman's age at first birth have grave implications for a roller coaster of life events such as education, worklife and completed family size. The results of this study found that the mean age at first birth for the cohort was 0.6 years higher than for marriage and 1.9 years higher than for sex debut. This finding suggests that the birth of the first child, in most instances, was preceded by sexual debut and then marriage. Similar analysis but for 43 countries found that the mean age at first birth was greater than the mean age at first marriage, which was also greater than the mean age at first sex for all regions [25]. A similar study conducted in Pakistan found that the hazards of birth increased in the first two years following marriage and their after declined [56]. 
Another significant aspect that affects CFS is education of women. We found that women with no education and primary education $(52 \%$ and $39.7 \%$ respectively) tended to have more children than those with secondary (3\%) and tertiary education (4.7\%). Even though noticeable progress has been attained, rural areas of sub-Saharan Africa still display low education levels for women $[25,57]$. Thus, the education atmosphere is not favorable to any meaningful change in CFS for rural women in the region [52,54]. Not only does education delay age at first birth, it also enhances the power of choice among women such that their consumption patterns enable them to live healthy and pursue healthy choices in child rearing [25]. Our findings show that in all the models, education attainment was inversely related to CFS. The lower the education level attained, the higher the CFS; but age at first marriage and first birth are positively related to education level attained. This, however, is expected as women who attend secondary and tertiary education are selective, such that the timing at which events occur intersect and compete with schooling age; much more in post primary than primary $[46,47]$. Numerous reasons have been advanced that cause the inverse relationship between a woman's education and fertility that include but not limited to superior autonomy among women, exposure to new gender norms and childbearing practices, improvement in information acquiring useful to women's health and their offspring. Women with more education are also selective in partner choice, have higher need for wealth and understand the costs that accrue or are forgone in timing of reproductive events.

Relatedly, women that reported having never used contraception were 6.9 times (95\% Cl: 3.3-8.5) (Model 2) more likely to have 1-3 children than 6 or more children compared to participants that have ever used contraceptive. This is an expected result because the variable "Ever used contraception" does not measure frequency of contraceptive use during the active childbearing years nor does it measure current use for those still bearing children. The best way of understanding the effect of contraceptive use on CFS is to retrospectively investigate the frequency of and reasons for contraceptive use for women at the height of their childbearing career. Education has also been cited as a source of instruments necessary for obtaining information that enhances women and girls' ability of comprehending and learning information regarding contraceptive use and the benefits of smaller families. It could be because education is not as widespread in rural areas that women there exhibited higher fertility behaviors than their urban counterparts. In terms of household wealth, our results indicate that the distribution of women by household wealth did not very much. The range was $18.2 \%(95 \% \mathrm{Cl}: 159-20-7)$ for lowest to $22.5 \%$ (95\% Cl: 19.9-25.1). Within household wealth classes, the highest proportions were recorded among women with 6 or more children. Table 4 model 2 shows that the higher the household wealth the less the risk of having 1-3 children relative to 6 or more children. The relationship between household wealth and CFS when CFS is 4-5 children was not statistically significant. This outcome could be as a result of measuring household wealth as current and not during their childbearing years or at the beginning of their childbearing period. Retrospective studies have this limitation in linking duration measures to point estimates.

\section{Conclusion}

Our findings align with several previous studies accentuating an inverse association between mother's age at marriage and first birth to CFS. Women that marry between age 15 and 18 years have a higher likelihood of having 6 or more children by the end of the reproductive period than their peers who marry later. Marriage is one significant predictor of CFS. While both age at first marriage and first birth are strongly associated with changes in CFS, our study further finds that poverty, low education attainment and low levels of contraceptive use increase the odds of a high CFS. Improvements in general education, especially post primary education among women will significantly contribute to a delay in timing of reproductive events. In addition, strengthening current child protection guidelines would ensure young girls get married and start childbearing at an age when they able to make informed choices and cope with social and economic challenges that come with motherhood.

\section{Declarations}

\section{Acknowledgements}

Not Applicable.

\section{Authors' contributions}

NM and TNM contributed to the conception and design of the study; NM and TNM did the literature search; NM, TNM and XCQ performed the statistical analysis; NM and TNM wrote the first draft of the manuscript. All authors contributed to manuscript revision, read, and approved the submitted version.

\section{Funding}

None.

\section{Availability of data and materials}

Data used in this article are available to bona fide researchers on request from the DHS program.

\section{Ethics approval and consent to participate}

Not applicable.

\section{Consent for publication}

Not applicable.

\section{Competing interests}

The authors declare no competing interest. 


\section{References}

1. Bourgeois-Pichat $J$ (2012) Social and biological determinants of human fertility in nonindustrial societies. Proceedings of the American Philosophical Society 111: 160-163.

2. Central Statistical Office (1997) Zambia Demographic and Health Survey 1996. Macro International Inc., Zambia.

3. Central Statistical Office (CSO), Ministry of Health (MOH), Tropical Diseases Research Centre (TDRC), University of Zambia (UNZA) (2009) Zambia Demographic and Health Survey 2007. Macro International Inc.

4. Marini MM (1981) Effects of the Timing of Marriage and First Birth on Fertility. J Marriage Fam 43: 7.

5. (1979) Age at marriage and fertility. Popul Rep Spec Top Monogr.

6. Anderson TM (2016) Three essays on the social, economic, and demographic causes and consequences of low fertility. Diss Abstr Int Sect A Humanit Soc Sci 77.

7. Ariho P, Nzabona A (2019) Determinants of Change in Fertility among Women in Rural Areas of Uganda. J Pregnancy 2019: 6429171.

8. Central Statistical Office, Ministry of Health, University of Zambia Teaching Hospital Virology Laboratory, University of Zambia Department of Population Studies, Tropical Diseases Research Centre, The DHS Program (2015) Zambia Demographic and Health Survey 2013-14.

9. Caselli G, Vallin J, Wunsch G (2006) Demography: Analysis and synthesis. Vol 1-4, Academic Press.

10. Ashraf QH, Weil DN, Wilde J (2013) The effect of fertility reduction on economic growth. Popul Dev Rev 39: 97-130.

11. University of Zambia (UNZA), Central Statistical Office (CSO), Macro International Inc (1993) Zambia Demographic and Health Survey 1992.

12. Central Statistical Office (CSO), Central Board of Health, ORC Macro (2003) Zambia Demographic and Health Survey 2001-2002. Calverton.

13. Ariho $P$, Kabagenyi $A$ (2020) Age at first marriage, age at first sex, family size preferences, contraception and change in fertility among women in Uganda: analysis of the 20062016 period. BMC Womens Health 20: 8.

14. Bongaarts J (2017) Africa's Unique Fertility Transition. Popul Dev Rev 43: 39-58.

15. Gerland P, Biddlecom A, Kantorová V (2017) Patterns of Fertility Decline and the Impact of Alternative Scenarios of Future Fertility Change in sub-Saharan Africa. Popul Dev Rev 43: 21-38.

16. Poulin M (2007) Sex, money, and premarital partnerships in southern Malawi. Soc Sci Med 65: 2383-2393.

17. Caroline K, Alex E (2009) Factors associated with sexual abstinence among adolescents in four Sub-Saharan African countries. Afr J Reprod Health 11: 111-132.

18. Clark S, Kabiru C, Mathur R (2010) Relationship transitions among youth in Urban Kenya. J Marriage Fam 72: 73-88.

19. Lloyd CB (2010) The role of schools in promoting sexual and reproductive health among adolescents in developing countries.

20. Biddlecom A, Gregory R, Lloyd CB, and Mensch B (2007) Premarital sex and schooling transitions in four subSaharan African countries. Poverty Gender Youth Work 5: 337-350.
21. Grant MJ, Hallman KK (2008) Pregnancy-related school dropout and prior school performance in KwaZulu-Natal, South Africa. Stud Fam Plann 39: 369-382.

22. Clark S, Mathur R (2012) Dating, Sex, and Schooling in Urban Kenya. Stud Fam Plann 43: 161-174.

23. Central Statistical Office Zambia (CSO) (2012) 2010 Census of Population and Housing.

24. Zambia Statistical Agency (ZSA), Ministry of Health, University Teaching Hospital Virology Laboratory, The DHS Program (2019) Zambia Demographic and Health Survey 2018.

25. Bongaarts J, Mensch BS, Blanc AK (2017) Trends in the age at reproductive transitions in the developing world: The role of education. Popul Stud 71: 139-154.

26. Gilles Pison (2017) The Population of the World (2017). Popul Soc 547.

27. United Nations Children's Fund (UNICEF) Generation 2030 | Africa. New York.

28. Muhoza DN, Broekhuis A, Hooimeijer P (2014) Variations in desired family size and excess fertility in East Africa. Int J Popul Res 2014: 1-11.

29. Quisumbing AR, Maluccio JA (2003) Resources at marriage and intrahousehold allocation: Evidence from Bangladesh, Ethiopia, Indonesia, and South Africa. Oxf Bull Econ Stat 65: 283-327.

30. Glick P, Handy C, Sahn DE (2015) Schooling, marriage, and age at first birth in Madagascar. Popul Stud 69: 219236.

31. Lesthaeghe R, Kaufmann G, Meekers D, Universiteit V (1989) The nuptiality regimes in sub-Saharan Africa. In: Lesthaeghe R, Reproduction and Social Organization in Sub-Saharan Africa. University of California Press, Berkelry/ Los Angeles.

32. van de Walle E (1993) Recent Trends in Marriage Ages. In: Foote KA, Hill KH, Martin LG, Demographic Change in SubSaharan Africa. The National Academies Press.

33. Garenne M (2004) Age at marriage and modernisation in sub-Saharan Africa. South African J Demogr 9: 59-79.

34. Lloyd CB, Behrman JR, Stromquist NP, Cohen B (2005) The changing transitions to adulthood in developing countries: Selected studies.

35. Mensch BS, Grant MJ, Blanc AK (2006) The changing context of sexual initiation in sub-Saharan Africa. Popul Dev Rev 32: 699-727.

36. Mensch BS, Singh S, Casterline JB (2005) Trends in the timing of first marriage among men and women in the developing world. Chang Transitions to Adulthood Dev Ctries Sel Stud 202: 118-171.

37. Ortega JA (2014) A Characterization of World Union Patterns at the National and Regional Level. Popul Res Policy Rev 33: 161-188.

38. Shapiro D, Gebreselassie T (2014) Marriage in SubSaharan Africa: Trends, Determinants, and Consequences. Popul Res Policy Rev 33: 229-255.

39. Westoff CF (1992) Age at marriage, age at first birth, and fertility in Africa. World Bank Technical Paper 169.

40. Hertrich $\vee(2017)$ Trends in age at marriage and the onset of fertility transition in sub-Saharan Africa. Popul Dev Rev 43: $112-137$ 


\section{Available Datasets. The DHS Program.}

42. Population Council, United Nations Population Fund, Government of the Republic of Zambia (2017) Child Marriage in Zambia. Lusaka.

43. Government of the Republic of Zambia, United Nations Children's Fund (UNICEF) (2015) Qualitative study of child marriage in six districts of Zambia. Hong Kong.

44. Government of the Republic of Zambia (2016) Contitution of Zambia. Zambia.

45. Child Frontiers (2020) Young marriage, parenthood and divorce in Zambia. Oxford.

46. StataCorp LLC (2016) Stata version 14•2.

47. Erens B, Phelps A, Clifton S, Mercer CH, Tanton C, et al. (2014) Methodology of the third british national survey of sexual attitudes and lifestyles (Natsal-3). Sex Transm Infect 90: 84-89.

48. Sedgwick P (2014) Cross sectional studies: Advantages and disadvantages. BMJ 348: 8-10.

49. Setia MS (2016) Methodology series module 3: Crosssectional studies Maninder. Indian J Dermatol 61: 261-264.

50. Carlson MDA, Morrison RS (2009) Study design, precision, and validity in observational studies. J Palliat Med 12: 7782.
51. United Nation Department of Economic and Social Affairs (2017) Population Facts: Household size and composition around the world.

52. Manda S, Meyer R (2018) Age at first marriage in malawi: A bayesian multilevel analysis using a discrete time-to- event model. J R Stat Soc Ser A 168: 439-455.

53. Maswikwa B, Richter L, Kaufman J, Nandi A (2015) Minimum marriage age laws and the prevalence of child marriage and adolescent birth: Evidence from sub-Saharan Africa. Int Perspect Sex Reprod Health 41: 58-68.

54. Jayaraman A, Gebreselassie T, Chandrasekhar S (2009) Effect of conflict on age at marriage and age at first Birth in Rwanda. Popul Res Policy Rev 28: 551-567.

55. Corno L, Hildebrandt N, Voena A (2017) Age of Marriage, Weather Shocks, and the Direction of Marriage Payments. Natl Bur Econ Res.

56. Gangadharan L, Maitra P (2003) The effect of education on the timing of marriage and first birth in Pakistan. J Quant Econ 1: 114-133.

57. Channon MD, Harper S (2019) Educational differentials in the realisation of fertility intentions: Is sub-Saharan Africa different? PLoS One 14: e0219736. 